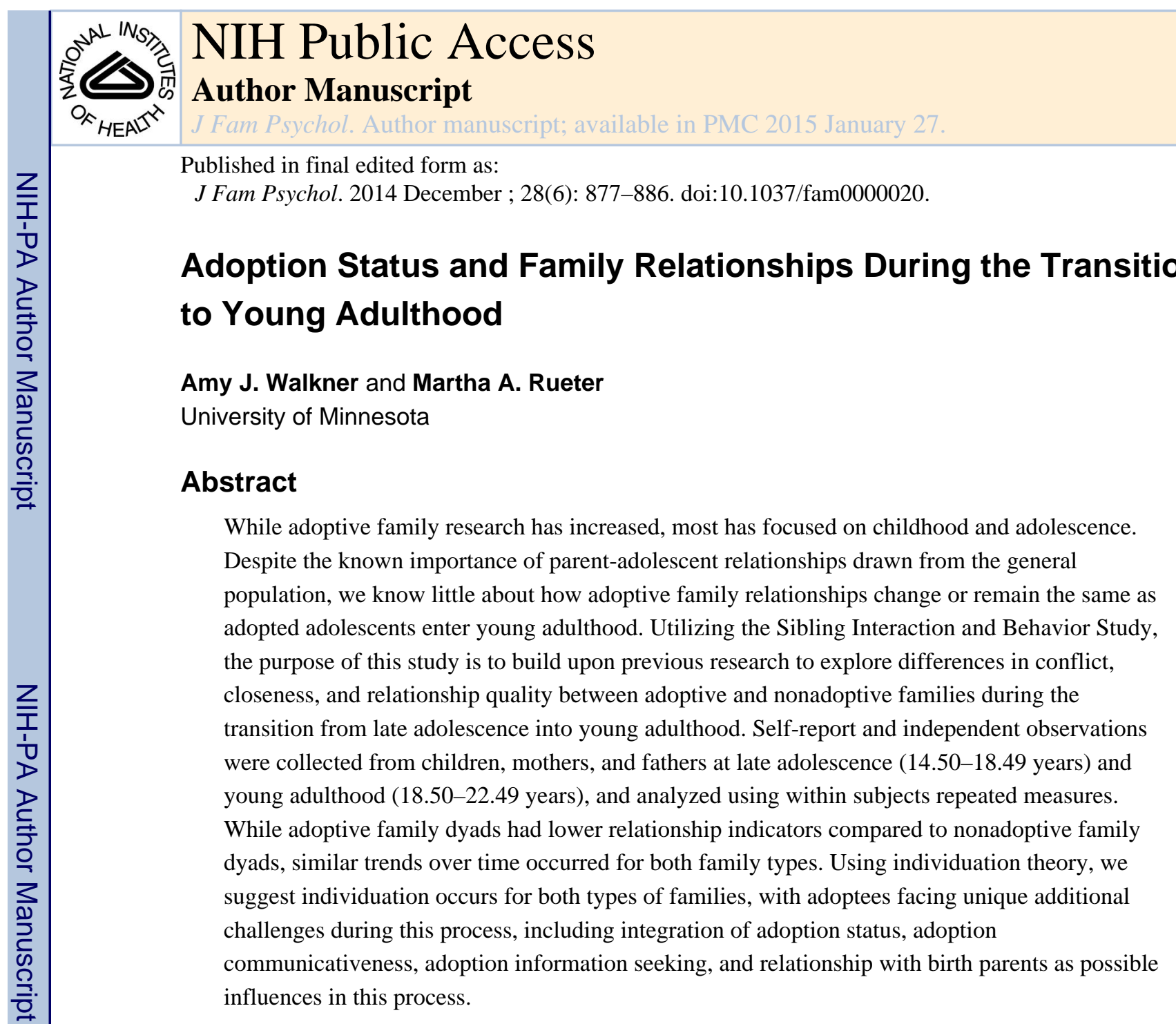

\title{
Keywords
}

adolescence; adoption; family relationships; young adulthood

Over the last 30 years adoption has become a less secretive and increasingly valid way to build a family, resulting in the increased prevalence of adoptive families within the U.S. There are approximately 1.5 million adoptees under the age of 18 years in the U.S., accounting for just over $2 \%$ of the population (Nickman et al., 2005). Additionally, it is estimated $60 \%$ of Americans have a personal connection to adoption, by knowing an adoptee, knowing someone who has adopted, or knowing someone who has placed a child for adoption (Evan B. Donaldson Institute, 1997). The increased prevalence of adoptive families confirms the importance of understanding adoptive family relationships.

As stigma surrounding adoption has decreased, adoptive family research has increased, focusing on parent-child relationships during childhood and adolescence. Evidence exists for a relationship between secure adoptive family attachment and healthy development starting in infancy (Ainsworth, 1989; Brodzinsky, 1987). Early adoption theory, inspired by Erikson's (1950) developmental stage theory, outlined unique normative challenges faced by adoptive families during childhood and adolescence. Notable differences included adoptive 
families' ability to deal with adoption grief and loss in a healthy way and the ability to create a comfortable environment conducive to questions and open communication about adoption (Brodzinsky, 1987; Kirk, 1984). Within the family context, as they age from childhood through adolescence, adoptees may face increased vulnerability while navigating identity development complicated by adoption status and lack of cognitive ability necessary to process complex and abstract grief related to adoption (Brodzinsky, 1987).

Adolescent adoptive family research has furthered our knowledge of family relationships through the study of conflict, closeness, and relationship quality. Comparisons between adoptive, nonadoptive, single, and step families found adoptive mothers reported higher conflict compared to mothers in other family types (Lansford, Ceballo, Abbey, \& Stewart, 2001). Research on family closeness has shown adopted adolescents reporting both lower and equal levels of closeness with adoptive mothers during adolescence compared to nonadopted adolescents (Burrow, Tubman, \& Finley, 2004; Lansford et al, 2001; Sobol, Delaney, \& Earn, 1994). Relationship quality comparisons between adoptive and nonadoptive families found adoptees rated their families lower than nonadoptive families (Sharma, McGue, \& Benson, 1995).

More recently, two studies have made significant contributions to furthering our understanding of adolescent adoptive family relationships. First, Loehlin, Horn, and Ernst (2010), asked identified mid-life adoptees and nonadoptees to complete a retrospective measure of family closeness on their parents during adolescence. Parents and siblings of the identified adults were also asked to complete retrospective measures of family closeness on the identified adult during adolescence, and were asked to rate their perceived level of closeness that existed between other family members and the identified adult. Results supported a general level of closeness within families, regardless of family type. Second, Rueter, Keyes, Iacono, and McGue (2009) assessed warm, supportive communication; parental control; and conflict in adoptive and nonadoptive parent-adolescent dyads using self-report and independent observer ratings. Self-report measures indicated less warm, supportive communication and increased conflict in adoptive families, while independent observers found greater levels of conflictual behavior in adoptive families initiated by adolescents towards their parents, when compared to their onadoptive counterparts (Rueter, Keyes, Iacono, \& McGue, 2009).

While adoptive family relationship research is progressing, a notable gap exists in our knowledge. While we have some information about adoptive family relationships during adolescence, we know little about how adoptive family relationships change or remain the same as adolescents enter young adulthood. Therefore, there is a need to examine adoptive family relationships during the transition to adulthood. The purpose of this study is to explore family relationships among adoptive and nonadoptive families during the transition from late adolescence into young adulthood.

\section{Individuation Theory}

The transition from adolescence into young adulthood presents a unique set of challenges not only for the individual, but also the family. Individuation theory provides a unique lens 
from which to view the transition from adolescence into young adulthood, due to its use as a theoretical framework for adult parent-child relationship research and its focus on parentchild relationships over time (Buhl, 2008; Smollar \& Youniss, 1989).

Modern theoretical work defines individuation as a complex process, starting in childhood and extending through young adulthood, during which children decrease dependence on parents while remaining connected to them (Youniss \& Smollar, 1985). Of particular concern for the present study, during late adolescence into young adulthood parent-child relationships are expected to shift from unilateral parental authority to a mutual and cooperative parent-child relationship (Buhl, 2008; Youniss \& Smollar, 1985). Inherently, this shift brings about change in the parent-child relationship, consisting of either a new, balanced relationship with equally distributed authority or disengagement with parents (Hoffman, 1984; Smollar \& Youniss, 1989). Ultimately, a child's task during this developmental stage is to construct an adult self that develops from the context of the parent/ child relationship (Pipp, Shaver, Jennings, Lamborn, \& Fischer, 1985).

How individuation occurs within a family has strong implications for parent-child relationships in late adolescence and young adulthood. Successful individuation has been associated with numerous positive outcomes, including greater relationship quality with parents and increased closeness with mothers (Buhl, 2008). Additionally, the presence of strong emotional ties in families has been found to be unaffected by familial conflict (Buhl, 2008). Unsuccessful individuation, including detached or severely separated parent-child relationships, has been associated with low levels of closeness and lower family relationship quality (Buhl, 2008; Ingoglia, Lo Coco, Liga, \& Lo Cricchio, 2011). Failure to successfully individuate also has ramifications outside of the parent-child relationship, as long-term conflict with parents may foster mistrust and insecurity in future relationships (Hoffman, 1984).

While individuation theory has been used to contextualize relationship changes within families during the transition from adolescence into young adulthood, virtually little is known how this process might differ for parents and children in adoptive families. Given the unique tasks inherent in adoptive family life (Brodzinsky, 1987; Kirk, 1984), it is reasonable to believe the process of individuation might be complicated for adoptive parent-child dyads.

\section{Importance of Close Family Relationships}

Despite the absence of adoptive family relationship research on the transition from late adolescence into young adulthood, family relationship research in the general population has supported these relationships as key across the life span. Ainsworth's (1989) classic attachment research, as well as contemporary research, has promoted caregiver-infant attachment relationships as enduring and important to functioning and adaptation into adulthood (Collins \& Laursen, 2004; Englund, Kuo, Puig, \& Collins, 2011). Beyond infancy, research on positive family relationships in middle childhood and early adolescence has shown more positive parent-adolescent relationships and increased mother-adolescent closeness in young adulthood (Aquilino, 1997; Belsky, Jaffee, Hsieg, \& Silva, 2001). 
Family relationship studies during adolescence revealed mothers and adolescents reported a strong continuity of parent-child relationship quality across time, as well as the importance of family relationship quality during the transition from adolescence into young adulthood (Aquilino, 1997; Collins \& Laursen, 2004; Thornton, Orbuch, \& Axinn, 1995). Despite research on adolescents' need for separation and individuation (Grotevant \& Cooper, 1985; Smollar \& Youniss, 1989), positive family relationships have been shown to continue throughout the transition into young adulthood and to influence adolescent well-being (van Wel, Ter Bogt, \& Raaijmakers, 2002). Evidence of the continued influence of family relationships throughout the life span is illustrated by an adult child's response to the death of parent. While the grieving process may resolve, internal working models of the parent continue to influence the adult child indefinitely (Ainsworth, 1989).

Family relationship research from the general population allows us to make conclusions about the importance of family relationships, including adoptive families. First, it is evident close relationships provide a significant context for one's development and adaptation (Koepke \& Denissen, 2012; Noack \& Buhl, 2005). Second, continuity exists in parent-child relationships across the life span (Bucx \& van Wel, 2008; Collins \& Laursen, 2004). Third, parent-child relationships influence adolescent and young adult adjustment, psychosocial and psychological well-being. Changes in these relationships correspond with changes in general well-being, psychological stress, suicidal thoughts, and global adaptive functioning, providing evidence of the effects parent-child bonds have beyond infancy (Bucx \& van Wel, 2008; Englund et al., 2011; van Wel, Linssen \& Abma, 2000). Finally, those with histories of high-quality interpersonal relationships are likely to be better adjusted as adults (Englund, et al., 2011).

\section{Family Relationship Change Over Time}

Family relationships during the transition from late adolescence into young adulthood have been conceptualized in the general population in a number of ways, including dimensions such as parent-child conflict, parent-child closeness, and overall parent-child relationship quality.

\section{Conflict}

Past research on parent-adolescent conflict was predicated on the "storm and stress" model, which maintained some conflict was a normative part of the parent-adolescent experience, a model since refuted (see Arnett, 1999; Montemayor, 1986; Steinberg, 2001). Early assumptions were replaced with the view that some parent-adolescent conflict is more likely to occur during adolescence, but with individual variation in the degree which this conflict is experienced (Arnett, 1999; Belsky et al., 2001; Montemayor, 1986; Noack \& Buhl, 2005). Within this line of thought, slight increases in parent-adolescent conflict during early adolescence have not been shown to disrupt family relationships (Steinberg, 2001), and additional research has shown higher conflict at mid-adolescence compared to early adolescence (Collins \& Laursen, 2004; De Goede, Branje, \& Meeus, 2009). Despite research showing slight increases in conflict during early adolescence, support has also existed for a linear decrease in parent-adolescent conflict, particularly during the transition from mid to late adolescence (De Goede et al., 2009; Collins \& Laursen, 2004; Laursen, Coy, \& Collins, 
1998). As adolescents reach young adulthood, studies of conflict in parent-adolescent relationships reinforced decline, particularly when compared to early adolescence (Laursen et al, 1998).

\section{Closeness}

Parental reports of parent-adolescent closeness have shown stable or increased levels of closeness into young adulthood (Aquilino, 1997; Tubman \& Lerner, 1994). Likewise, adolescents have also self-reported linear increases in closeness with mothers throughout adolescence, with slight variations into young adulthood (Belsky et al., 2001; Rice \& Mulkeen, 1995). A linear increase in father-adolescent closeness has also been found, with adolescent boys reporting closer, more intimate relationships with fathers (Collins \& Laursen, 2004; Rice \& Mulkeen, 1995). Findings on parent-adolescent closeness support the importance of parent-child relationships through adolescence on the maintenance of close parent-child relationships into young adulthood.

\section{Relationship quality}

The parent-adolescent relationship quality literature can be generally categorized in two ways. First, adolescent reported family relationship quality from adolescence into young adulthood has supported differences between mother-adolescent relationships and fatheradolescent relationships (Levitt, Silver, \& Santos, 2007; Pipp et al., 1985; Thornton et al., 1995). Second, parent-adolescent relationship quality research has supported differences between late adolescence and young adulthood (Levitt et al., 2007; Thornton et al., 1995).

Beginning in early adolescence and enduring until young adulthood, adolescents have selfreported closer, more satisfied relationships with mothers compared to fathers (Levitt et al., 2007; Thornton et al., 1995), marked by equal responsibility and friendliness in comparison to father-adolescent relationships (Pipp et al., 1985). When parent-adolescent relationships are viewed during the transition from adolescence into young adulthood after high school, similar trends in relationship quality can be seen. Adolescents reported greater general improvement and higher overall satisfaction with mothers compared to fathers during the transition to adulthood (Levitt et al., 2007; Thornton et al., 1995). This difference remained after the transition to adulthood, with young adults reporting significant improvement in relationships and greater satisfaction with mothers (Levitt, et al., 2007).

\section{Measuring Adoptive Family Relationships}

Previous adoptive family relationship research has suffered from methodological inadequacies. Historically, adoption research has utilized inadequately sized and unrepresentative samples (Palacios \& Brodzinsky, 2010). Our study utilized a robust data set representative of the region from which it was drawn (McGue et al., 2007). Additionally, adoption research has relied on cross-sectional studies due to lack of longitudinal data sets specific to adoption research. Our study utilized a longitudinal data set that measured change in adoptive and nonadoptive family relationships over four years, from adolescence into young adulthood, which allowed an in-depth look at adoptive family relationship change over time. 
Measurement issues have also plagued adoption research, and have included overreliance on retrospective data (due to lack of longitudinal adoption studies), use of singular reporting perspectives (usually the adoptee), and data collection only using self-report. Our study addressed these issues by using a longitudinal study design that collected data on family relationships during late adolescence and young adulthood from every study participant (mother, father, and child), on all parent-adolescent dyadic relationships, through self-report measures as well as observational family measures.

\section{Current Study}

Based upon what is known about the importance of parent-adolescent relationships in the general population, the next important step in adoptive family research is to study the transition from late adolescence into young adulthood. Utilizing data from the Sibling Interaction and Behavior Study (SIBS; McGue et al., 2007) the current study builds upon previous adoptive family research through self-reported and observed family relationship indicators at late adolescence (W1) and young adulthood (W2), by considering whether differences in family relationships exist between adoptive and nonadoptive family dyads from late adolescence into young adulthood. Based upon existing literature it was hypothesized; H1) adoptive families will report and be observed to have significantly more conflict than nonadoptive families, H2) there will not be a significant difference in selfreported and observed closeness between adoptive and nonadoptive families, and H3) adoptive families will report and be observed to have significantly lower relationship quality than nonadoptive families.

\section{Method}

Sample

Data used in this study were provided by adoptive and nonadoptive participants of the SIBS study (McGue et al., 2007; Rueter et al., 2009), a longitudinal study investigating sibling influence on drug and alcohol use. Data were collected in two waves; W1 in 1998 and W2 four years later. Adoptive families were accessed through the three largest private adoption agencies in Minnesota, and nonadoptive families were accessed through Minnesota state birth records. Contact information for both groups was located through birth or adoption records and public records, and eligible families were contacted via phone. Researchers located $90 \%$ of the identified adoptive families and $85 \%$ of the nonadoptive families.

All families were contacted via phone to determine eligibility. Eligible adoptive families were required to have two children ages 11-21 years, with at least one adoptee placed permanently in the home before two years of age (average age at placement was 4.7 months). The second child was required to be nonbiologically related to the adoptee, but could be biologically or nonbiologically related to their parents. Nonadoptive families were required to have biologically related siblings ages 11-21 years. For all families, adolescents were required to be no further than five years apart in age and have no physical or cognitive handicap rendering them unable to participate in an all-day assessment. Adoptive families formed through kinship, special needs, and foster care adoption were not recruited. Two methods assessed recruited family representativeness. First, $73 \%$ of families that did not 
participate in the study were asked questions to assess their representativeness compared to families that did participate in the study. The recruited sample was generally representative of the population it was drawn from. Second, U.S. census data specific to Minnesota was compared to the study sample, confirming representativeness (McGue et al., 2007).

Self-report data and independent observations were collected, resulting in child-reports, mother-reports, father-reports, and independent observations for children and mothers. Unlike the Rueter et al. (2009) sample, child age was restricted in order to focus on family relationships from late adolescence into young adulthood. Thus, families were included if their children were $14.50-18.49$ years $\left(M_{\mathrm{age}}=16.34, S D=0.91\right)$ at $\mathrm{W} 1$ and $18.50-22.49$ years $\left(M_{\text {age }}=19.84, S D=0.96\right)$ at W2 (59\% of the Rueter et al., 2009 sample). The majority of children identified as White (52.5\%), followed by Asian/Pacific Islander (39.9\%), Other/ Mixed (4.0\%), Hispanic (2.3\%), and Black (1.3\%). Mothers $\left(M_{\text {age }}=46.87, S D=4.21\right.$ at W1 and $M_{\text {age }}=50.32, S D=4.19$ at W2) were predominantly White (98\%), and most fathers $\left(M_{\mathrm{age}}=48.75, S D=4.27\right.$ at $\mathrm{W} 1$ and $M_{\mathrm{age}}=52.70, S D=1.84$ at $\left.\mathrm{W} 2\right)$ also identified as White (97\%).

Final sample sizes varied for specific measures. A sample of 473 children $\left(n_{\text {adoptive }}=272\right.$, $\left.n_{\text {nonadoptive }}=201\right)$ self-reported on relationships with mothers, and 467 children $\left(n_{\text {adoptive }}=\right.$ $267, n_{\text {nonadoptive }}=200$ ) self-reported on relationships with fathers. For observation, a sample of $475\left(n_{\text {adoptive }}=274, n_{\text {nonadoptive }}=201\right)$ child-mother observations were analyzed. Fathers were not invited to participate in the W2 observation task. For parents, 470 mothers

( $\left.n_{\text {adoptive }}=271, n_{\text {nonadoptive }}=199\right)$ self-reported on relationships with their children and 345 ( $\left.n_{\text {adoptive }}=206, n_{\text {nonadoptive }}=139\right)$ mother-child observations were analyzed. A sample of 418 fathers $\left(n_{\text {adoptive }}=248, n_{\text {nonadoptive }}=170\right)$ self-reported on relationships with their children.

\section{Procedures}

Families visited the University of Minnesota to participate in the study. Parents and adolescents completed informed consents in the lab. Both waves consisted of assessments which included the independently completed self-report measures by each family member and the independent observations of family members used in this study. Families were reimbursed travel costs and given a small honorarium (McGue et al., 2007).

Family observations occurred in a room decorated like a living room/dining room with family members completing the observation tasks around a dining table (Rueter et al., 2009). Hidden video cameras recorded the observation tasks and families were aware of being recorded. At W1 families participated in two 5-minute interactions with instructions given by a trained interviewer who left the room during videotaping. For the first interaction, families were asked to reach consensus on what a Rorschach inkblot resembled. For the second interaction families were given a moral dilemma involving a husband without money who needed to purchase medicine for his sick wife (Kohlberg, 1981). Families were asked to discuss whether the man should steal the drug to save his wife's life and whether he should steal the drug for a stranger in need. At W2, families participated in a 15-minute interaction with instructions given by a trained interviewer who left the room during videotaping. Families were asked to discuss and attempt to resolve up to three family problems identified 
on previously completed questionnaires, starting with the problem that caused the most disagreements. Families were told to continue to the next problem after they had resolved the previous problem. Families that completed the discussion before time ended were given a set of cards containing questions about family life to discuss.

\section{Measures}

Self-report family relationships-Self-reported family relationships, measured as conflict and closeness, were assessed at W1 and W2 utilizing the Parental Environment Questionnaire (PEQ; Elkins, McGue, \& Iacono, 1997). The PEQ is a 50-item questionnaire created to assess specific aspects of parent-child relationships, with identical questions tailored for a mother's rating, father's rating, and child's rating. Family members were asked to rate aspects of their family relationships on a four point scale ranging from 1 (definitely true) to 4 (definitely false). Mothers and fathers independently completed questionnaires on each child separately, and each child independently completed separate questionnaires on their mother and father, resulting in four dyadic measures of self-reported parent-child relationships (mother-child, father-child, child-mother, and child-father).

Self-reported parent-child conflict was assessed using the 12-item Conflict with Parent subscale of the PEQ, with higher scores indicating higher conflict. Examples of questions answered by mothers and fathers included, "Often there are misunderstandings between my child and me," and "My child and I often get into arguments." Examples of questions answered by children included, "Often there are misunderstandings between my parent and myself" and "My parent and I often get into arguments." Items were summed and interitem reliability ranged from 0.88 to 0.91 .

Self-reported parent-child closeness was assessed utilizing the 12-item Involvement with Parent subscale of the PEQ, with higher scores indicating higher closeness. Examples of questions answered by mothers and fathers included, "My child and I don't have much to talk about when we are together," and "My child doesn't seem to feel very close to me." Examples of questions answered by children included, "My parent and I don't have much to talk about when we are together," and "I don't feel very close to my parent." Items were summed and interitem reliability ranged from 0.82 to 0.89 .

Observed family relationships-Observed family relationships were assessed using the SIBS Rating Scores (Rueter et al., 2009), adapted from the Iowa Family Interaction Rating Scales (IFIRS; Melby et al., 1998). IFIRS has been used in more than a dozen research studies with consistently high interrater reliabilities assessed as intraclass corrections (ICC) ranging from 0.55 to 0.85 (Melby \& Conger, 2001). Trained observers viewed the family interaction tasks at W1 and W2, rating an individual's behavior toward each of the other family members using a nine point scale ranging from 1 (not at all characteristic of the person) to 9 (mainly characteristic of the person). Observers were required to complete 100 hours of training and to pass written and observation examinations before being allowed to view observation tapes (Rueter et al., 2009). Reliability was assessed through random selection of $25 \%$ of the videotapes to be rated by a second observer. Observers were required to attend biweekly meetings for continued training. 
Observed mother-child conflict was measured utilizing the SIBS Hostility scale. This scale measured the degree which a family member displayed hostile, angry, critical, disapproving, and/or rejecting behavior towards another family member's actions, appearance, and state through verbal and nonverbal cues. ICCs ranged from .50 to .90.

Observed mother-child closeness was measured by aggregating four SIBS subscales into a single closeness scale. The Warmth/Support scale measured the degree which a family member expressed care, concern, and support toward another family member through verbal and nonverbal cues (ICC range: .56 - .85). The Listener Responsiveness scale measured the behavior of a family member as a listener, assessing the degree they showed interest in, acknowledged, and validated another family member (ICC range: $.34-.90$ ). The Communication scale measured the behavior of a family member as a communicator, assessing the degree which they positively or negatively conveyed their needs to other family members (ICC range: .60 - .83). The Prosocial scale measured the behavior of a family member as competently and effectively relating with another family member (ICC range: $.44-.83)$.

Overall observed family relationships were measured using the SIBS Relationship Quality scale, comprised of the observer's evaluation of the quality of the mother-child dyad.

Relationship Quality was measured using a nine point scale ranging from 1 (negative) to 9 (positive), with higher scores indicating a more positive dyadic relationship. Both persons in the dyad receive the same score. ICCs ranged from .56 to .90 .

\section{Data Analyses}

Analytic plan-Testing this study's hypotheses required that we examine differences in family relationships between adoptive and nonadoptive family dyads from late adolescence into young adulthood. To accomplish this, within subjects repeated measures analyses were used. These analyses compared self-reported and observed conflict, closeness, and overall family relationship quality between adoptive and nonadoptive parent-child dyads (Adoption Status) over two time points (Time). To determine if adoptive compared to nonadoptive family relationships changed over time, each model tested the interaction between adoption status and time (Adoption Status x Time). Based upon previous research citing relationship differences between son-parent and daughter-parent relationships (Collins \& Laursen, 2004; Levitt et al., 2007; Rice \& Mulkeen, 1995; Youniss \& Smollar, 1985), biological sex was used as a covariate in all analyses. Preliminary analyses showed differences between inracial and transracial adoptive families were not significant, and therefore was not included as a control. Correlated family error, due to family level data analyzed at the dyadic level, was accounted for with linear mixed modeling in SPSS 21.0.

Missing variable analysis-Missing demographic data ranged from 0\% to $9.6 \%$. Missing data for self-reported family relationships ranged from $2.3 \%$ to $6.7 \%$ at $\mathrm{W} 1$ and $10.0 \%$ to $30.3 \%$ at $\mathrm{W} 2$. Missing observation data ranged from $3.4 \%$ to $4.4 \%$ at $\mathrm{W} 1$ and $28.4 \%$ to $31.2 \%$ at W2. T-test and chi square comparisons between participants with complete data and those with missing data were performed for all study variables. Statistically significant differences were found, but in almost all cases mean differences 
were negligible. For example, adolescent participants with incomplete data self-reported more conflict with mothers at W1 than adolescents with complete data $\left(M_{\text {incomplete }}=2.03\right.$ and $\left.M_{\text {complete }}=1.89 ; t=-2.06, p=.041\right)$. The majority of missing data resulted from nonparticipation of fathers (W1 self-report missing: $2.3 \%$ to $3.3 \%$, W2 self-report missing: $24.4 \%$ to $30.3 \%$ ), resulting in one statistically significant finding. Fathers with complete self-report data had younger children at W2 $\left(M_{\text {complete }}=19.77, M_{\text {incomplete }}=20.00 ; t=2.22\right.$, $p=.027)$. All missing data were imputed through expectation maximization using SPSS 21.0 .

\section{Results}

Mean scores for self-report and observed family relationships are shown in Tables 1 and 2. Tables 3 and 4 present results from statistically comparing these means. Our first hypothesis, that adoptive families would have significantly more conflict than nonadoptive families, was supported. Specifically, adoptees reported higher conflict, $F(1,607)=12.85, p<.001$, and were observed to have higher conflict, $F(1,542)=4.02, p=.046$, with adoptive mothers in comparison to their nonadoptive counterparts. For parents, adoptive mothers reported higher conflict with adoptees than nonadoptive mothers, $F(1,596)=30.89, p<.001$, and adoptive fathers reported higher conflict with adoptees than nonadoptive fathers, $F(1,537)=5.39, p$ $=.021$. Across all dyads interactions between Time and Adoption Status were not significant.

Our second hypothesis, that no significant difference in closeness between adoptive and nonadoptive families would exist, was not supported. With the exception of observed closeness, adoptive mother-adoptee dyads had lower closeness when compared to their nonadoptive counterparts. Specifically, adoptees reported lower closeness with adoptive mothers than nonadoptees, $F(1,497)=14.81, p<.001$. Adoptive mothers reported lower closeness with adoptees in comparison to nonadoptive mothers, $F(1,623)=8.62, p=.003$, with a significant interaction occurring between Time and Adoption Status, $F(1,530)=$ $5.70, p=.017$, meaning adoptive mothers reported a greater decrease in closeness over time with adoptees compared to their nonadoptive counterparts. For observed closeness, adoptive mothers were observed to have higher closeness with adoptees compared to nonadoptive mothers, $F(1,342)=4.21, p=.041$, with a significant interaction occurring between Time and Adoption Status, $F(1,343)=4.26, p=.040$, meaning adoptive mothers were observed to have a greater increase in closeness with adoptees compared to nonadoptive mothers.

Our third hypothesis, that adoptive families would have significantly lower relationship quality than nonadoptive families, was not supported. Tables 3 and 4 also report associations found for the sex control variable. Overall, these results show that daughters, regardless of adoption status, tended to have less conflictual and closer relationships with their parents than sons.

\section{Discussion}

Our study extends knowledge of adoptive families by investigating family relationships during the transition from late adolescence into young adulthood. Overall, differences in 
relationship levels existed between adoptive and nonadoptive family dyads, while trends over time were similar for both family types. We view parent-child dyadic differences using individuation theory and discuss the possible effects of variables unique to adoptive families influencing our findings.

Adoptive family dyads generally had lower mean relationship indicators than nonadoptive dyads, particularly between adoptees and adoptive mothers. Our findings of higher selfreported and observed conflict, as well as lower reported closeness by adoptees towards their adoptive mothers, supports previous research indicating higher conflict (Lansford et al., 2001; Rueter et al., 2009) and lower closeness (Burrow et al., 2004; Lansford et al., 2001) in adoptive families compared to nonadoptive families. Adoptive mothers and adoptive fathers also reported higher conflict with adoptees, again supporting existing research (Lansford et al., 2001; Rueter et al., 2009). Closeness findings among adoptive parents towards adoptees were mixed, with adoptive mothers reporting lower closeness with adoptees compared to nonadoptive mothers, while adoptive mothers were observed to have higher closeness. These results partially support previous research of self-reported lower or no difference in closeness (Lansford et al., 2001; Loehlin, Horn, \& Ernst, 2010) between adoptive and nonadoptive families. Additionally, within the adoptive parent-adoptee dyads, effect sizes for adoptive mothers were found to be greater than effect sizes for adoptive fathers. Future research should focus on what these effect sizes mean in term of differences in parenting between adoptive mothers and adoptive fathers.

Overall, trends over time for adoptive and nonadoptive family relationship indictors were found to be more similar than different, with the exception of adoptive mother closeness. In comparison to nonadoptive mothers, adoptive mothers reported a significant decrease in closeness over time with adoptees, while they were observed to have a significant increase in closeness over time. Similar to Rueter et al. (2009), our findings of differences between self-reported and observed closeness might be attributable to methodology, with self-report capturing more global processes of closeness within adoptive mother-adoptee dyads and independent observations capturing the specific behavior of adoptive mothers' closeness towards adoptees. For example, self-report questions such as "My child prefers not to talk about his personal problems with me" or "My child and I do not do a lot of things together" might be reporting on an adoptee's behavior towards their adoptive mother rather than the adoptive mother's behavior towards the adoptee, while independent observations focus solely on an adoptive mother's behavior towards the adoptee, resulting in observations of increased closeness by adoptive mothers towards adoptees.

\section{Individuation and Adoptive Families}

Individuation theory (Grotevant \& Cooper, 1985; Youniss \& Smollar, 1985) may play a particularly salient role in our results. While adoptive family dyads reported lower relationship indicators compared to nonadoptive family dyads, similar trends over time occurred for both family types. As discussed below, this suggests individuation occurs for both types of families, with adoptees possibly facing additional challenges during this process. 
While all young adults undergo individuation, the process of decreased parental dependence while remaining connected (Smollar \& Youniss, 1989), adoptees are unique in their need to incorporate adoption into this process. Adoption may be particularly relevant to one's life, and its importance may change over time. Higher levels of adoption preoccupation have been associated with greater alienation and lower levels of trust with adoptive parents (Kohler, Grotevant, \& McRoy, 2002). Particularly for girls, higher adoption preoccupation may contribute to emotional withdrawal from parents and periods of intense reflection (Kohler et al., 2002; Benson, Sharma, \& Roehlkepartain, 1994), all which may have potentially debilitating effects on adoptive family relationships during young adulthood.

Numerous adoption related variables become particularly salient for adoptees during the transition from late adolescence into young adulthood, possibly influencing individuation and accounting for relationship differences between adoptive and nonadoptive families. Family unwillingness to discuss adoption is associated with individuation difficulties and family connectedness, including feeling adoption as deviant (Brodzinsky, 1987). Many adopted adolescents undertake the normative experience of information seeking during this time, gathering unknown information about adoption stemming from lack of adoption knowledge (Wrobel \& Dillon, 2009). Typically, seeking is thought about during adolescence and acted upon in young adulthood (Skinner-Drawz, Wrobel, Grotevant, \& Von Korff, 2011), occurring during individuation. Adoptive parents may impact individuation by revealing unknown adoption information they previously felt the adoptee was not mature enough to hear, influencing an adoptees' need to seek new information and possibly causing the adoptee to feel guilty or disloyal in desiring additional information (Wrobel \& Dillon, 2009). Adopted young adults may chose not to seek out information for fear of hurting parents, thus affecting adoptive parent-child relationships (Brodzinsky, 1987; Wrobel \& Dillon, 2009). Additionally, contact interest with one's birth parents is a form of identity work connected to significant developmental milestones that occur during individuation, and reaching the age of majority allows some adoptees access to adoption information in the U.S. (Kohler et al., 2002; Wrobel, Kohler, Grotevant, \& McRoy, 2004). Contact with biological parents may be a particularly sensitive issue in adoptive parent-young adult relationships, with adoptive parents fearing decreased family relationship quality with a search (Brodzinsky, 1997). For most families, individuation culminates in launching children from home to establish themselves separately from parents (Aquilino, 1997; Bucx \& van Wel, 2008), but adoptive families' history of loss may render them vulnerable to this transition (Hartman \& Laird, 1990), fearing lack of biological tie may distance their adopted child from them (Brodzinsky, 1997). While adoptees face many unique issues during individuation, we know little about how these issues affect adoptive family relationship quality during young adulthood.

\section{Limitations}

Two limitations of our research need mentioning. First, while self-report data for each dyadic relationship were collected at $\mathrm{W} 1$ and $\mathrm{W} 2$, independent observation data were only collected for mothers and children at W1 and W2, since only mothers were invited to the lab at W2 with their young adult for the second videotaped interaction. Regardless, our study's methodology remains strong through its use of self-report and independent observational 
data collected at two time points. Second, information regarding pre-placement adversities was unavailable for our sample. Our intention was not to diminish the unique experiences inherent in each adoption type, rather our results serve as a starting point to further limited knowledge of adoptive family relationships during the transition to young adulthood.

Our use of biological sex as a covariate revealed significant effects of biological sex on parent-child relationships during the transition from late adolescence into young adulthood. Higher conflict was found between sons, fathers, and mothers over time compared to daughters, while higher closeness and relationship quality were found between mothers and daughters compared to sons. Areas for future research include investigation of the effect of biological sex on parent-child relationships in adoptive families. Additionally, future research would benefit from focusing on the influence of adoption type on family relationships during this transition, and the potential impact of pre-adoption adversity factors on adoptive parent-child relationships.

\section{Conclusion}

Our research adds valuable knowledge to the understanding of adoptive family relationships by extending previous work from adolescence into young adulthood, through use of a longitudinal, multi-reporter, multi-method data collection design. It is important to note that while significant differences in relationship indicators were found between adoptive and nonadoptive families, the magnitude of these differences were quite small. While conflict levels were higher in adoptive families, these scores were within a normative range of conflict. Our results have particular implications for researchers, therapists, and adoption professionals. Specifically, our results challenge assumptions that adoptive families are dysfunctional and professionals working with adoptive families must be wary not to pathologize adoption status.

Nevertheless, differences exist between adoptive and nonadoptive families. These results represent a starting point in distinguishing between adoption-related issues and normative developmental issues in late adolescence and young adulthood. Future adoptive family relationship research needs to move beyond the deficit approach comparing adoptive/ nonadoptive family differences, to investigating family processes that influence and shape healthy adoptive families.

\section{References}

Ainsworth MD. Attachments beyond infancy. American Psychologist. 1989; 44:709-716. [PubMed: 2729745]

Aquilino WS. From adolescent to young adult: A prospective study of parent-child relations during the transition to adulthood. Journal of Marriage and Family. 1997; 59:670-686.

Arnett JJ. Adolescent storm and stress, reconsidered. American Psychologist. 1999; 54:317-326. [PubMed: 10354802]

Belsky J, Jaffee S, Hsieh K, Silva PA. Child-rearing antecedents of intergenerational relations in young adulthood: A prospective study. Developmental Psychology. 2001; 37:801813.10.1037/0012-1649.37.6.801 [PubMed: 11699754]

Benson, PL.; Sharma, AR.; Roehlkepartain, EC. Growing up adopted. Minneapolis, MN: Search Institute; 1994. 
Brodzinsky DM. Adjustment to adoption: A psychosocial perspective. Clinical Psychology Review. 1987; 7:25-47.

Brodzinsky, DM. Infertility and adoption adjustment: Considerations and clinical issues. In: Leiblum, S., editor. Infertility. New York: John Wiley \& Sons, Inc; 1997. p. 246-262.

Bucx F, van Wel F. Parental bond and life course transitions from adolescence to young adulthood. Adolescence. 2008; 43:71-88. [PubMed: 18447081]

Buhl HM. Significance of individuation in adult child-parent relationships. Journal of Family Issues. 2008; 29:262-281.10.1177/0192513X07304272

Burrow AL, Tubman JG, Finely GE. Adolescent adjustment in a nationally collected sample: Identifying group differences by adoption status, adoption subtype, developmental stage and gender. Journal of Adolescence. 2004; 27:267-282.10.1016/j.adolescence.2004.03.004 [PubMed: 15159088]

Collins, A.; Laursen, B. Parent-adolescent relationships and influences. In: Lerner, R.; Steinberg, L., editors. Handbook of Adolescent Psychology. 2. Hoboken, N.J: John Wiley \& Sons, Inc; 2004. p. 331-361.

De Goede IH, Branje SJ, Meeus WH. Developmental changes in adolescents' perceptions of relationships with their parents. Journal of Youth and Adolescence. 2009; 38:75-88.10.1007/ s10964-008-9286-7 [PubMed: 19636793]

Elkins IJ, McGue M, Iacono WG. Genetic and environmental influences on parent-son relationships: Evidence for increasing genetic influence during adolescence. Developmental Psychology. 1997; 33:351-363. [PubMed: 9147842]

Englund MM, Kuo SI, Puig J, Collins WA. Early roots of adult competence: The significance of close relationships from infancy to early adulthood. International Journal of Behavioral Development. 2011; 35:490-496.10.1177/0165025411422994 [PubMed: 23372278]

Erikson, EH. Childhood and Society. New York: W.W. Norton \& Company; 1950. Eight stages of man; p. 219-234.

Evan B. Donaldson Institute. Benchmark adoption survey: Report on the findings. Washington DC: Princeton Survey Research Associates; 1997. Retrieved from http://www.adoptioninstutute.org/ research/instituteresearch.php

Grotevant HD, Cooper CR. Patterns of interaction in family relationships and the development of identity exploration in adolescence. Child Development. 1985; 56:415-428. [PubMed: 3987416]

Hartman, A.; Laird, J. Family treatment after adoption: Common themes. In: Brodzinsky, D.; Schechter, M., editors. The Psychology of Adoption. New York: Oxford University Press; 1990. p. 221-239.

Hoffman JA. Psychological separation of late adolescents from their parents. Journal of Counseling Psychology. 1984; 31:170-178.

Ingoglia S, Lo Coco A, Liga F, Lo Cricchio MG. Emotional separation and detachment as two distinct dimensions of parent-adolescent relationships. International Journal of Behavioral Development. 2011; 35:271-281.10.1177/0165025410385878

Kirk, DH. Shared Fate. 2. Port Angeles, WA: Ben-Simon; 1984.

Koepke S, Denissen JJ. Dynamics of identity development and separation-individuation in parent-child relationships during adolescence and emerging adulthood- A conceptual integration. Developmental Review. 2012; 32:67-88.10.1016/j.dr.2012.01.001

Kohlberg, L. Essays on moral development, Vol. 1: The philosophy of moral development. New York: Harper and Row; 1981.

Kohler JK, Grotevant HD, McRoy RG. Adopted adolescents' preoccupation with adoption: The impact on adoptive family relationships. Journal of Marriage and Family. 2002; 64:93-104.

Lansford JE, Ceballo R, Abbey A, Stewart AJ. Does family structure matter? A comparison of adoptive, two-parent biological, single-mother, stepfather, and stepmother households. Journal of Marriage and Family. 2001; 63:840-851.

Laursen B, Coy KC, Collins WA. Reconsidering changes in parent-child conflict across adolescence: A meta-analysis. Child Development. 1998; 69:817-832. [PubMed: 9680687] 
Levitt MJ, Silver ME, Santos JD. Adolescents in transition to adulthood: Parental support, relationship satisfaction, and post-transition adjustment. Journal of Adult Development. 2007; 14:5363.10.1007/s10804-007-9032-5

Loehlin JC, Horn JM, Ernst JL. Parent-child closeness studied in adoptive families. Personality and Individual Differences. 2010; 48:149-154.10.1016/j.paid.2009.09.012

McGue M, Keyes M, Sharma A, Elkins I, Legrand L, Johnson W, Iacono W. The environments of adopted and non-adopted youth: Evidence on range restriction from the Sibling Interaction and Behavior Study (SIBS). Behavioral Genetics. 2007; 37:449-462.10.1007/s10519-007-9142-7

Melby, JN.; Conger, RD. The Iowa Family Interaction Rating Scales: Instrument summary. In: Kerig, P.; Lindahl, K., editors. Family observational coding systems: Resources for systemic research. Muhwah, NJ: Erlbaum; 2001. p. 33-58.

Melby, JN.; Conger, RD.; Book, R.; Rueter, MA.; Lucy, L.; Repinski, D. The Iowa family interaction rating scales. 5. Institute for Social and Behavioral Research, Iowa State University; Ames, Iowa: 1998. Unpublished manuscript

Montemayor R. Family variation in parent-adolescent storm and stress. Journal of Adolescent Research. 1986; 1:15-31.10.1177/074355488611003

Nickman SL, Rosenfield AA, Fine P, Macintyre JC, Pilowsky DJ, Howe RA, Sveda SA. Children in adoptive families: Overview and update. Journal of the American Academy of Child and Adolescent Psychiatry. 2005; 44:987-995.10.1097/01.chi.0000174463.60987.69 [PubMed: 16175103]

Noack P, Buhl HM. Relations with parents and friends during adolescence and early adulthood. Marriage \& Family Review. 2005; 36(3-4):31-51.10.1300/J002v36n03_03

Palacios J, Brodzinsky D. Review: Adoption research: Trends, topics, outcomes. International Journal of Behavioral Development. 2010; 34:270-284.10.1177/0165025410362837

Pipp S, Shaver P, Jennings S, Lamborn S, Fischer KW. Adolescents' theories about the development of their relationships with parents. Journal of Personality and Social Psychology. 1985; 48:9911001. [PubMed: 3989677]

Rice KG, Mulkeen P. Relationships with parents and peers: A longitudinal study of adolescent intimacy. Journal of Adolescent Research. 1995; 10:338-357.10.1177/0743554895103003

Rueter MA, Keyes MA, Iacono WG, McGue M. Family interactions in adoptive compared to nonadoptive families. Journal of Family Psychology. 2009; 23:58-66.10.1037/a0014091 [PubMed: 19203160]

Sharma AR, McGue MK, Benson PL. The emotional and behavioral adjustment of United States adopted adolescents: Part I. An overview. Children and Youth Services Review. 1995; 18:83-100.

Skinner-Drawz BA, Wrobel GM, Grotevant HD, Von Korff L. The role of adoption communicative openness in information seeking among adoptees from adolescence to emerging adulthood. Journal of Family Communication. 2011; 11:181-197.10.1080/15267431003656587 [PubMed: 23926444]

Smollar J, Youniss J. Transformations in adolescents' perceptions of parents. International Journal of Behavioral Development. 1989; 12:71-84.10.1177/016502548901200104

Sobol MP, Delaney S, Earn BM. Adoptees' portrayal of the development of family structure. Journal of Youth and Adolescence. 1994; 23:385-401.

Steinberg L. We know some things: Parent-adolescent relationships in retrospect and prospect. Journal of Research on Adolescence. 2001; 11:1-19.

Thornton A, Orbuch TL, Axinn WG. Parent-child relationships during the transition to adulthood. Journal of Family Issues. 1995; 16:538-564.10.1177/019251395016005003

Tubman JG, Lerner RM. Affective experiences of parents and their children from adolescence to young adulthood: Stability of affective experiences. Journal of Adolescence. 1994; 17:81-98.

van Wel F, Linssen H, Abma R. The parental bond and the well-being of adolescents and young adults. Journal of Youth and Adolescence. 2000; 29:307-318.

van Wel F, ter Bogt T, Raaijamakers Q. Changes in the parental bond and the well-being of adolescents and young adults. Adolescence. 2002; 37:317-333. [PubMed: 12144162] 
Wrobel, GM.; Dillon, K. Adopted adolescents: Who and what are they curious about? In: Wrobel, G.; Neil, E., editors. International advances in adoption research for practice. West Sussex, U. K: Wiley-Blackwell; 2009. p. 217-244.

Wrobel GM, Kohler JK, Grotevant HD, McRoy RG. The family adoption communication (FAC) model. Adoption Quarterly. 2004; 7(2):53-84.10.1300/J145v07n02_04

Youniss, J.; Smollar, J. Adolescent relations with mothers, fathers, and friends. Chicago: The University of Chicago Press; 1985. 


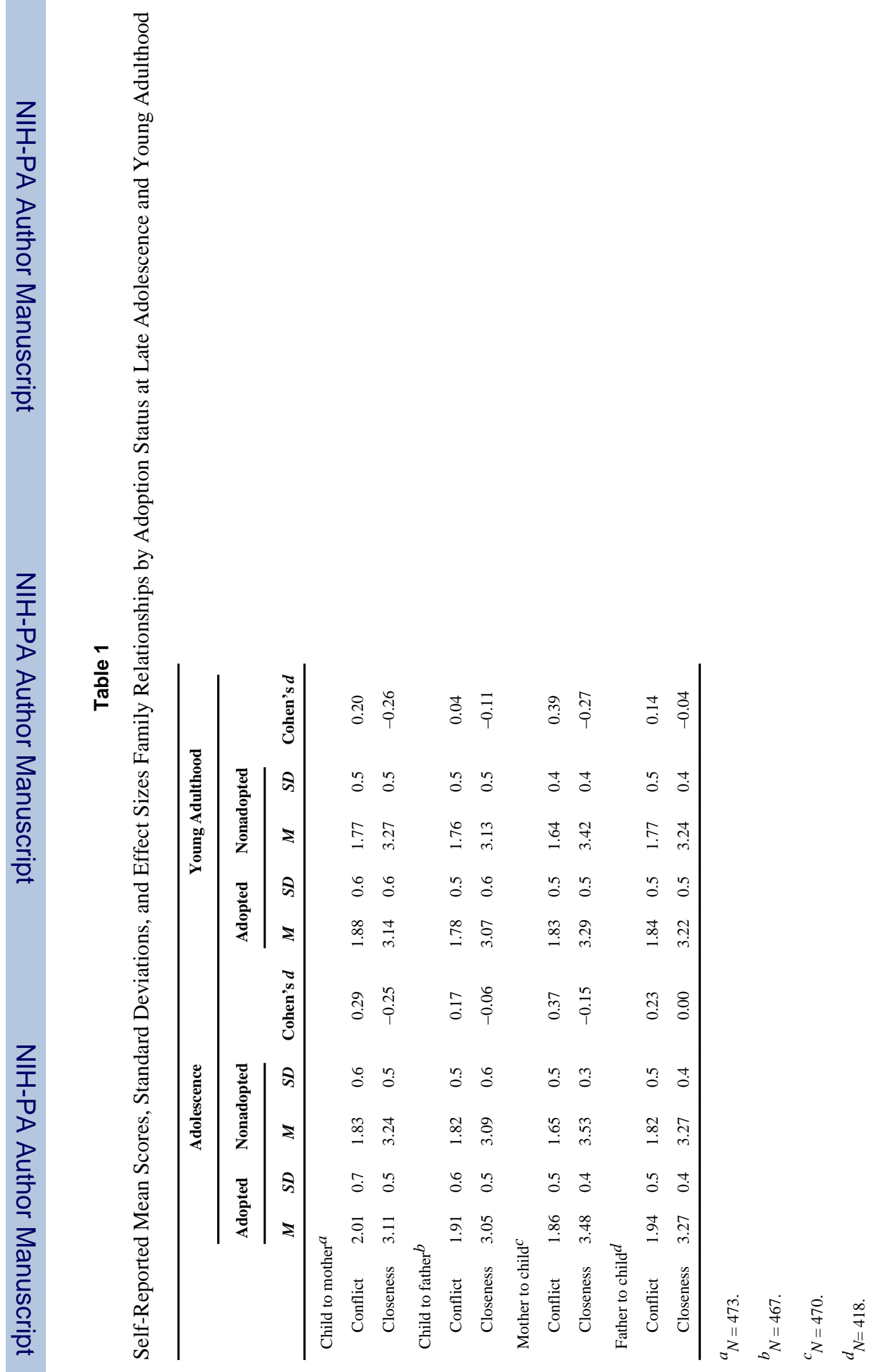




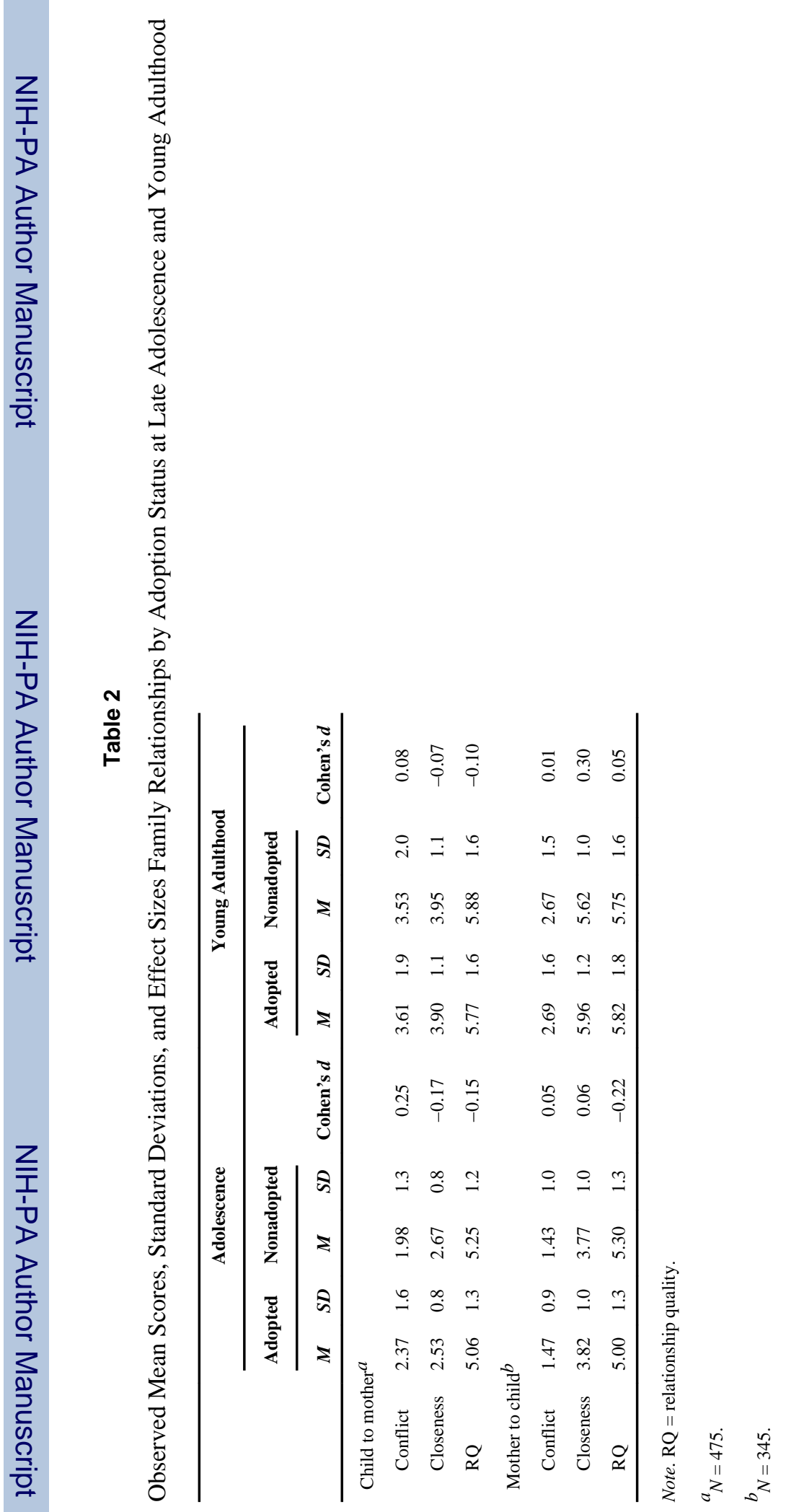




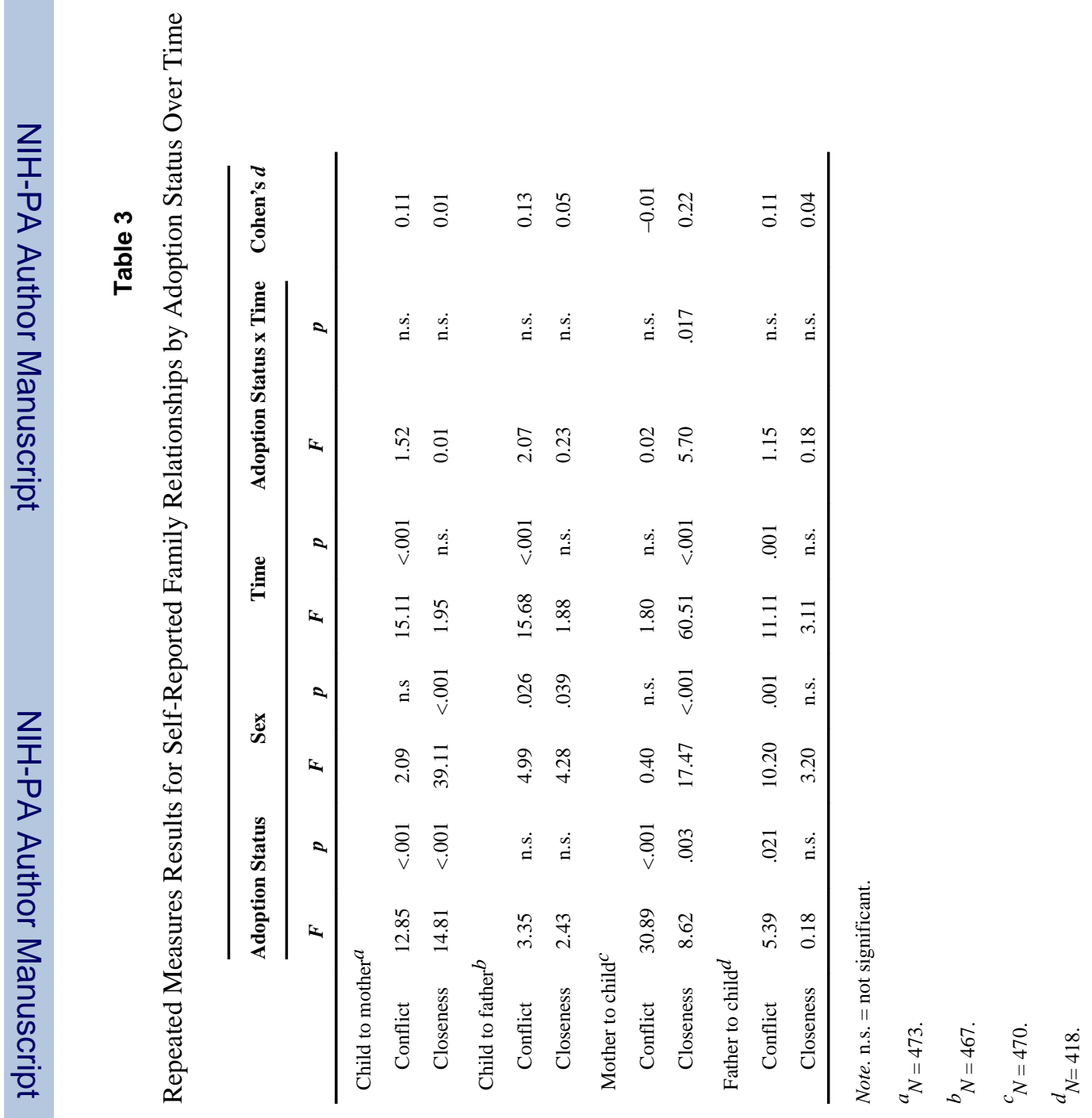


